\title{
Mobile Application for Electric Power Monitoring on Energy Consumptions at a Campus University
}

\author{
Murizah Kassim, Maisarah Abdul Rahman, Cik Ku Haroswati Che Ku Yahya, Azlina Idris \\ Faculty of Electrical Engineering, Universiti Teknologi MARA \\ 40450 UiTM Shah Alam, Malaysia
}

\begin{tabular}{l} 
Article Info \\
\hline Article history: \\
Received Feb 1, 2018 \\
Revised Apr 21, 2018 \\
Accepted Apr 27, 2018 \\
\hline
\end{tabular}

Keywords:

Mobile Applications Electric Power Monitoring Energy Consumptions Smart Meter

Live code

\begin{abstract}
This paper presents a research on electric power monitoring prototype mobile applications development on energy consumptions in a university campus. Electric power energy consumptions always are the issue of monitoring usage especially in a broad environment. University campus faces high used of electric power, thus crucial analysis on cause of the usage is needed. This research aims to analyses electric power usage in a university campus where implemented of few smart meters is installed to monitor five main buildings in a campus university. A Monitoring system is established in collecting electric power usage from the smart meters. Data from the smart meter then is analyzed based on energy consume on 5 buildings. Results presents graph on the power energy consume and presented on mobile applications using Live Code coding. The methodology involved the setup of the smart meters, monitoring and data collected from main smart meters, analyzed electrical consumptions for 5 buildings and mobile system development to monitor. A Live Code mobile app is designed then data collected from smart meter using ION software is published in graphs. Results presents the energy consumed for 5 building during day and night. Details on maximum and minimum energy consumption presented that show load of energy used in the campus. Result present Tower 1 saved most eenergy at night which is $65 \%$ compared to block 3 which is $8 \%$ saved energy although block 3 presents the lowest energy consumption in the working hours and non-working hours. This project is significant that can help campus facility to monitor electric power used thus able to control possible results in future implementations.
\end{abstract}

Copyright (C) 2018 Institute of Advanced Engineering and Science. All rights reserved.

\section{Corresponding Author:}

Murizah Kassim,

Faculty of Electrical Engineering, Universiti Teknologi MARA,

40450 UiTM Shah Alam, Malaysia.

Email: murizah@salam.uitm.edu.my

\section{INTRODUCTION}

Monitoring Power Efficiency is crucial today where some power metering and monitoring offers building operators and managers an insight into the usage, efficiency and potential problems associated with power consumption. Some effective power metering is done through the use of multifunction power meters which offer varying degrees of granularity and competencies to best match the application. Today's advancement of technology has presented many online and mobile applications that help users to monitor online and make system easier and faster management and monitoring process. Electric power consumption management needs some enhanced monitoring system design where usage of power electric can be measured [1]. The increasing complexity of the conventional grid due to population growth, advancement in technology and infrastructures which contribute immensely to instability, insecurity, and inefficiency and environmental energy sustainability calls for the use of renewable energy for sustainability of power supply. Some goals of Power Monitoring are to find an effective power monitoring that allows for the capture of 
critical power and energy usage and efficiency information. This data enables users to improve the effectiveness of critical systems, minimize waste, analyze plan and relocate demand, isolate power issues and proactively schedule maintenance or electric power upgrades. Investigation on photovoltaic [PV) panel with a direct-current (DC) fan cooling system where the DC fan cooling system enhanced the performance by raise the output power generated [2]. Others are like to allocate resources and gain in-depth analysis on power quality, consumption, and efficiencies. Predicting electricity price has now become an important task in power system operation and planning. An hour-ahead forecast provides market participants with the predispatch prices for the next hour. It is beneficial for an active bidding strategy where amount of bids can be reviewed or modified before delivery hours [3]. Electric power smart meter is tools used to measure amount of electrical energy. The difference between smart meter and common energy meters been used in Malaysia is a smart meter can display consumed results, consequently provide real inputs to the billing unit and most importantly collect the data consumed in a specific time frame. Meanwhile, a common energy meters can only read the energy consumed. In order to manage a big data for billing analytics can be one of the important technologies in the world, typically data from smart meters providing equipment and devices power usages in industries and in homes to save energy and reduce environmental pollution and flourish [4]. Recent industrial revolutions, IR 4.0 development focus to make life easier where mobile applications have been develop to monitor and manage real-time systems when data can be collected using a mobile device. Recent marketplace has challenged developers to develop more industrial and real-time applications for life quality management [5]. Various communications internet protocols are used in development of energy consumed system by installing smart meters. Data of electric usage then are kept on cloud database accessing from the readings by smart meter software and some smart meter reader is smart enough to create graphs of energy consumed by them self. The applications on the market today are mostly contain a large number of built-in advertising and commercial applications either used of online or web-based applications [6]. Hence, the development of the application creates more attention to real-time and online systems where the important of user's experience, system's function, monitoring and management is crucial [7, 8]. Other general way to monitor is transfers the data to the remote server by wired network using the PC-based system. This way has faced many problems because there are a lot of restrictions of system's requirements, such as the location of equipment [9]. Mobile apps recently the electronics market is becoming more popular especially in the smartphone market. It is an open source, some of the development tools are free, and so there are plenty of applications generated. This inspired the people to use the mobile apps. Furthermore, it provides a convenient platform for developers to spend less effort to realize their ideas. It also makes mobile apps can get further development [10].

Electric power usage monitoring are crucial due to global consensus on the necessity of decreasing the electrical consumption and changing the centralized paradigm of the grid to be distributed architecture [11]. This trend is being promoted in some cases by national or international commissions, as in the case of Europe, and although the penetration rate is not homogenous [12]. The implementation of smart metering is one of the important steps towards the realization of smart-grids [13]. The smart meter network is expected to monitor real-time status of the electrical network and communicate the required information to a control node capable of taking decisions [14]. There are numerous studies on the efficient management of smart meter data collection and post-processing. There are various standards set on smart meters [15]. This study focuses on a feasible measurement methodology implementable for smart meters for a building. Each measurement node is considered as a Wireless Sensor Node (WSN) [16]. Some government and private industry have invested billions of dollars to build the smart grid infrastructure to save energy, reduce cost, and increase reliability. The wide deployment of modern information technology into power grid control and communication networks makes higher resolution measurements available to more equipment at wider areas compared to the past. The management of large data for analytics is one of the significant technologies in the whole world especially monitoring electric power usage. Data enables users to improve the effectiveness of critical systems, minimize waste, analyze plan and relocate demand, isolate power issues and proactively schedule maintenance or electric power upgrades. Others are like to allocate resources and gain in-depth analysis on power quality, consumption, and efficiencies for industries and homes [17].

Energy storage is considered to be the ultimate solution for the ongoing discourse over renewable energy intermittency challenge, offering flexibility to counterbalance the net-load vagaries and inheriting the advantages of both fast- ramping generation and flexible loads [18]. Energy harvesting is an emerging technology to extend the lifetime of Internet of things (IoT), by harvesting energy from the environment or other energy sources and converting it to electrical energy. The deployment of energy harvesting in IoT bringing the promising benefits but faces unprecedented challenges such as low energy transfer efficiency, complex scheduling and resources allocation among multi-cells and unreliable energy resource. The refinements of the power inverter life spend and low industrial costs are widely presented in papers to reduced power. Economic effects caused by the lower power quality in the supply of energy, are growing up 
in almost all countries, thus the challenge is create the power solutions without attack the environment, with high quality [19]. Mobile application is one recent technology that supports IoT systems. It is a center stage in the for software development that deliver with easier and faster management. Mobile applications provides control services for high commitment systems which need to kept level of quality of services (QoS) [20]. This mobile app is used as test bed on the setup smart meters to monitor data on the energy consumptions in the university campus. It benefits facilities department and academics for research purposes. Creating a mobile app is an opportunity as new Industry Revolutions, IR 4.0 focus today where system can be mobility, online and real time tracking. Today, mmobile networks have achieved a high-level of acceptance and become the major Internet access approaches. Wireless technologies such as 5G, 4G and Long Term Evolution (LTE) network is expected to be leading mobile networking technology in the coming 5-10 years [21].

This research aims to analyses electric power usage in a campus university where implementation of few smart meters is installed to monitor 5 main buildings in a campus university. A Monitoring system is established in collecting electric power usage from the smart meters. Data from the smart meter then is analyzed based on energy consume on 5 buildings. Results presents graph on the power energy consume and presented on mobile applications using Live Code coding. A mobile app is designed then data collected from smart meter using ION software is published in graphs. Results presents the energy consumed for 5 building during day and night. Details on minimum, average and maximum data is presented that show load of energy used in the campus. This project is significant that can help campus facility to monitor electric power used thus able to control possible results in future implementations.

\section{METHODOLOGY}

\subsection{Research Flow}

Figure 1 shows a research flowchart from the installations of the smart meters, test bed, parameters setup, data collections and process of design mobile apps. Energy consumption is collected in a day for five (5) decided buildings that to be measured. Begin with connecting smart meters Ion 7650 software where data is collected in every 15 minutes time intervals in a day.
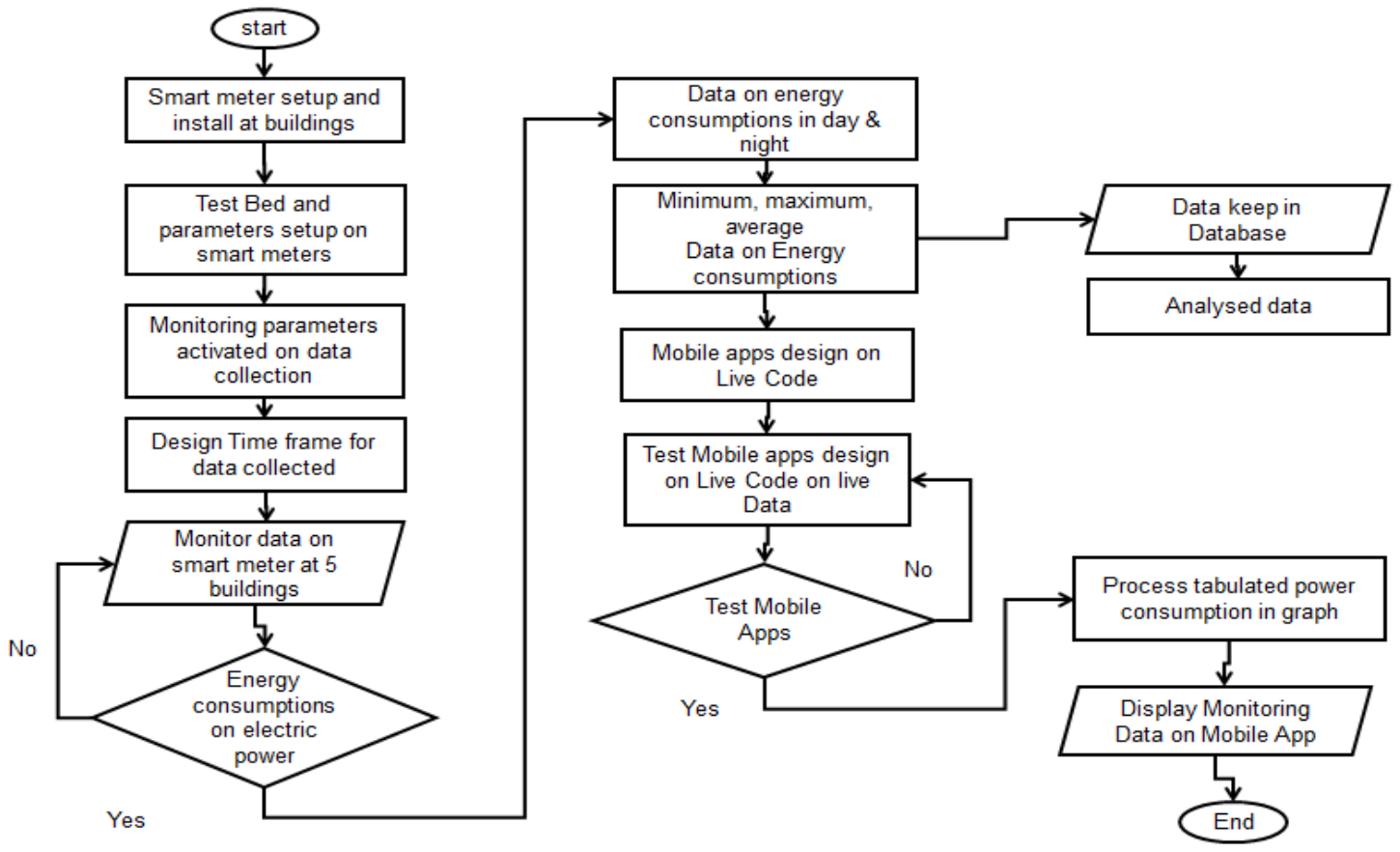

Figure 1. System Flow Chart

Collected data is kept in SQL database. Parameters on design analytics platform are confirmed and data are tabulated into graphs. The Live Code mobile application helps users handling to run mobile application. The application shows button that connected to the five selected main buildings in Campus 
University. Real-time system can be done through phone where the electric power energy consumptions are monitored.

\subsection{Architecture Diagram}

Figure 2 shows the architecture diagram of the designed smart metering system that explained how it is functions. Smart meters are installed in five identified buildings at block 3, 4, 5 are academic buildings and tower 1 and 2 are administration building for Faculty of Engineering. The system used SQL database that keeps data using SQL computing platform Database services take care of scalability and high availability of the database. Data then is analyzed where parameter input such as voltage, current and power is displayed on the smart meter. Moreover, data collection has been collected on SQL database and displayed on mobile phone. Synchronization between mobile applications and database are through where real-time data transmission is done for monitoring purpose.

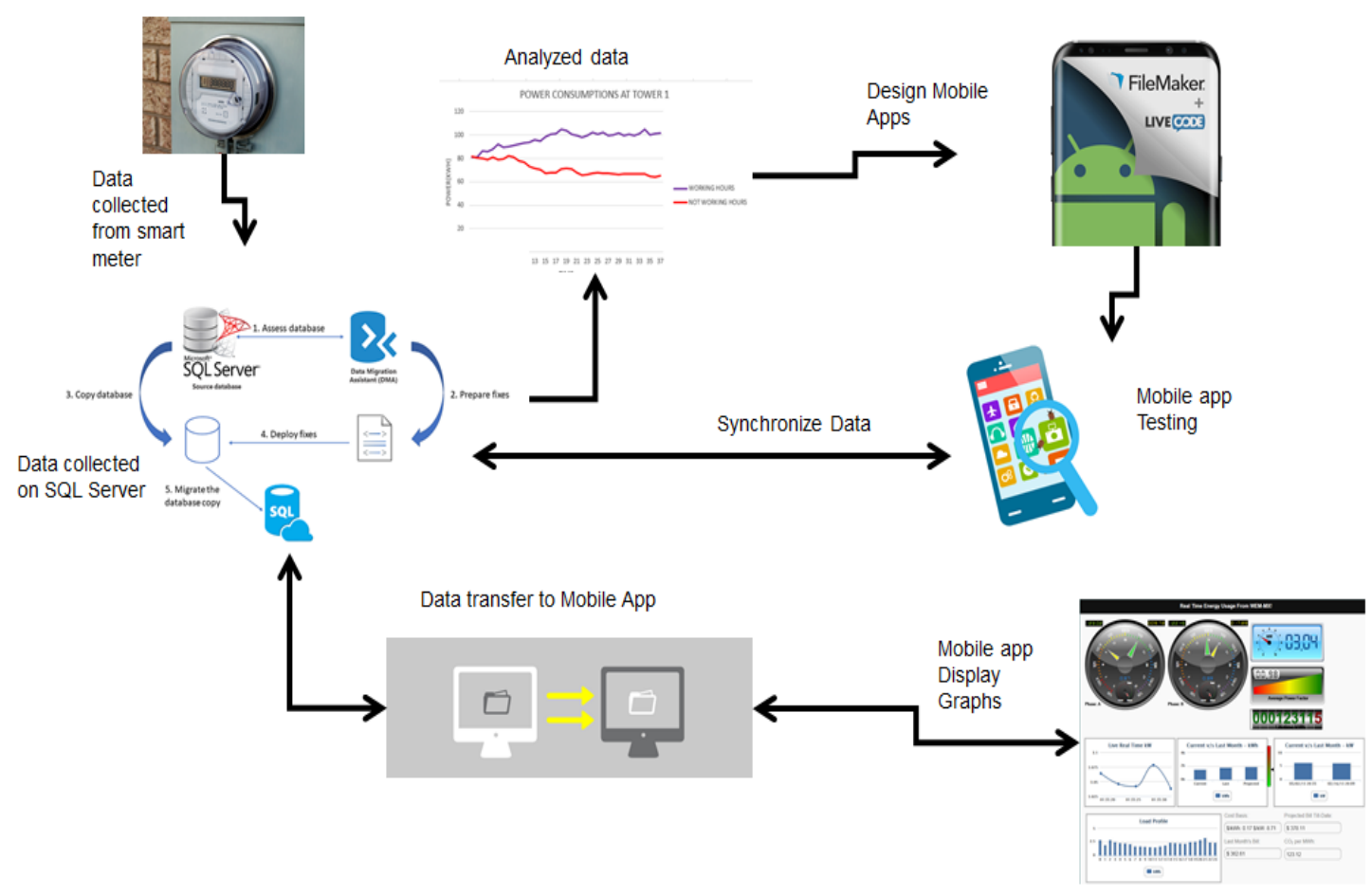

Figure 2. Architecture Diagram

\section{RESULTS AND DISCUSSION}

\subsection{Energy Consumption at Academic Buildings}

Figure 3 shows energy power consumptions comparison between working hours and non-working hours. Day time working hours is from 8 am to $5 \mathrm{pm}$ and non-working hours is from 8 pm to 5 pm at academic buildings which are block 3, 4 and 5. The entire three graph presents that reasonable data collection where day time energy consumption is higher than night time, which is non-working hours. The highest meter reading is during peak hour which is around 12 o'clock in the afternoon to 1 o'clock. It is because the electric consumed such as air conditions are turn on during that time, hence it can be considered that the because of the weather outside the building the electric used is high. The academics also used more electricity during day because of the working hours between 8 o'clock in the morning to 5 o'clock in the evening. Meanwhile at night, the academics consumed lower electricity used rather than at day because there is no working hours and class at night. Even though day time is more consume energy form night time but, there is still time that identified night time is higher than day time which is between $8.00 \mathrm{pm}$ to $10.00 \mathrm{pm}$ for block 3 and 5. The two overlapping hours is still under investigations scenario, maybe some labs are running which used a high energy power on the lab machine. 

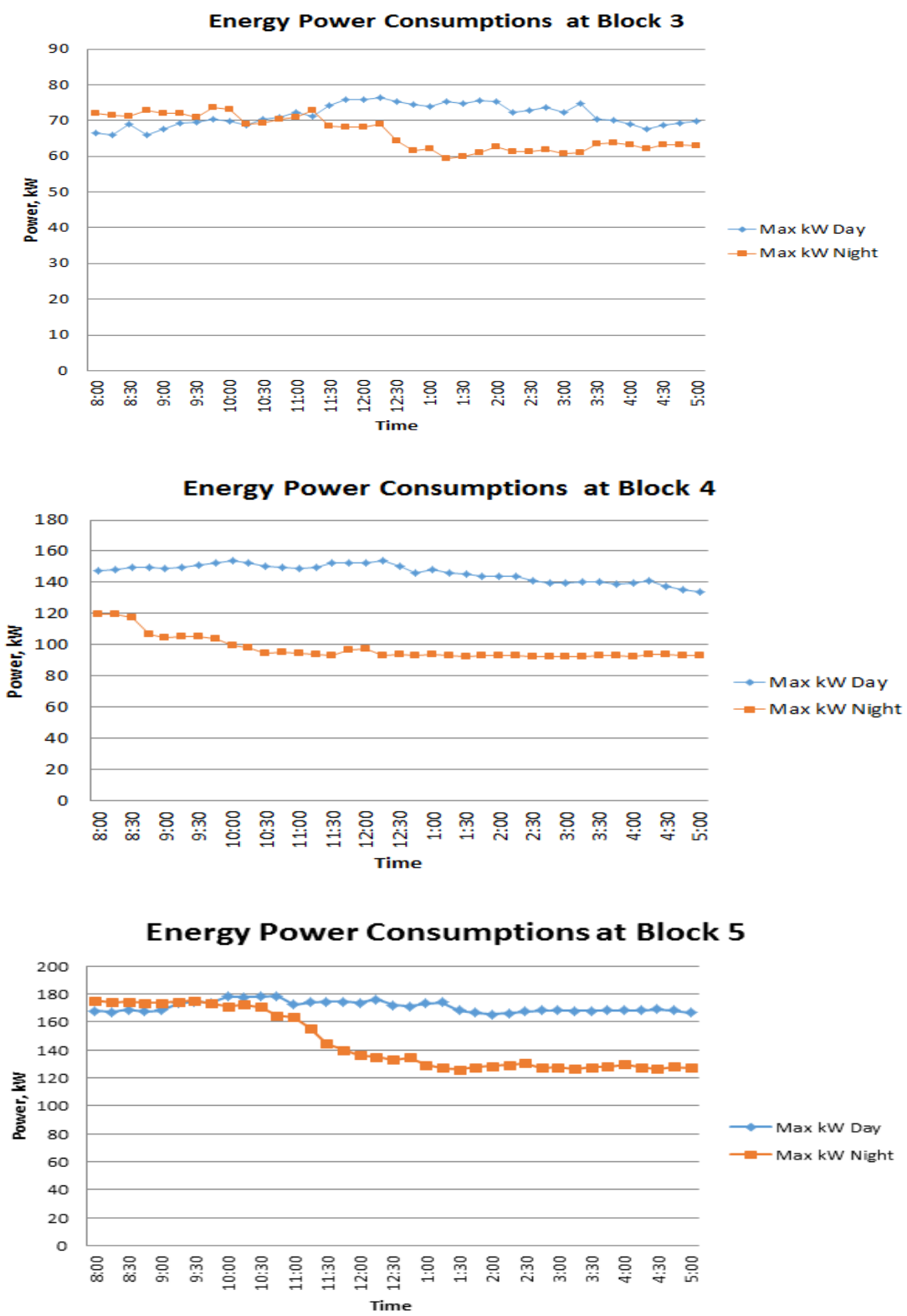

Figure 3. Power Energy Consumptions at Academic Buildings

Table 1 shows the comparison on the academic block building present that the highest energy used for day and night.

Table 1. Comparison Highest And Lowest Energy Comsumption at Academic Buildings

\begin{tabular}{lcrrr} 
& $\begin{array}{c}\text { Highest kW } \\
\text { Day }\end{array}$ & $\begin{array}{c}\text { Lowest kW } \\
\text { Day }\end{array}$ & $\begin{array}{c}\text { Highest kW } \\
\text { Night }\end{array}$ & $\begin{array}{c}\text { Lowest kW } \\
\text { Night }\end{array}$ \\
\hline Block 3 & 76.45 & 66.01 & 73.59 & 59.27 \\
Block 4 & 153.93 & 165.29 & 119.76 & 92.10 \\
Block 5 & 178.48 & 105.53 & 175.12 & 125.96 \\
\hline
\end{tabular}

\subsection{Energy Consumption at Administration’s Buildings}

Figure 4 shows Power Energy Consumptions at Administration's Buildings between working hours and non-working hours which are Tower 1 and 2. Both two graphs present that reasonable data collection where day time energy consumption is higher than night time, which is non-working hours. The highest meter reading is during peak hour which is between 10.30 am to 1.00 on in the afternoon. Result also 
presents that the administrations buildings also used more electricity during day because of the working hours between 8 o'clock in the morning to 5 o'clock in the evening. Meanwhile at night, administration consumed lower electricity than day time and also lower compared to academic buildings. There is no overlapping hour that shows a high energy power on night time with day time.
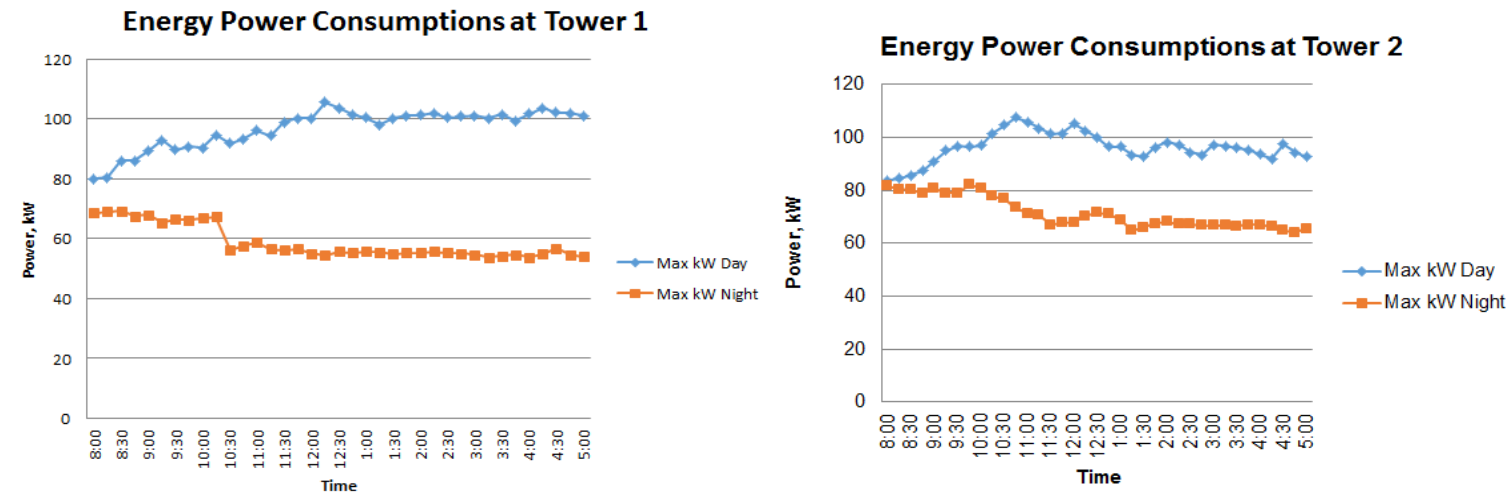

Figure 4. Power Energy Consumptions at Administration’s Buildings

Table 2 shows the comparison on the academic block building present that the highest energy used for day and night.

Table 2. Comparison Highest And Lowest Energy Comsumption at Administration’s Buildings

\begin{tabular}{|c|c|c|c|c|}
\hline & Highest kW & Lowest kW & Highest kW & Lowest kW \\
\hline & Day & Day & Night & Night \\
\hline Tower 1 & 105.53 & 79.89 & 69.32 & 53.84 \\
\hline Tower 2 & 107.66 & 83.76 & 82.26 & 64.04 \\
\hline
\end{tabular}

\subsection{Comparison Maximum Energy Consumption in Five Buildings}

Figure 5 shows a comparison of maximum electric power energy consumption in all 5 analyzed buildings that present that block 5 usage the highest electric power compared to others at day time. The lowest usage is Block 3 as an academic building. Tower 1 and Tower 2 present quite similar graph of usage for administrations buildings.

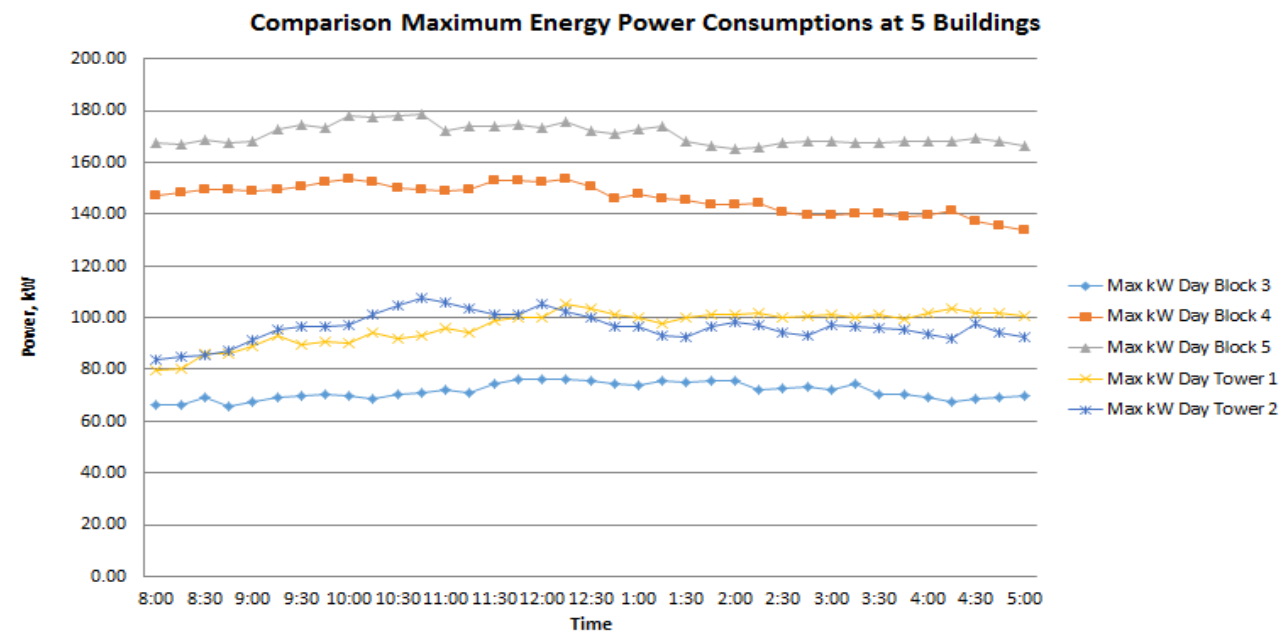

Figure 5. Maximum Power Energy Consumptions at Five Buildings 
Table 3 shows comparison between the average of power energy consumption on all buildings for day and night which is for working hours and non-working hours. Analyzed data presents that based on average used between day and nights, some energy saved is calculated where block 3, 4 and 5 save energy at the percentage of $8 \%, 50 \%$ and $17 \%$ at night time. Administrations building saved energy percentage at $65 \%$ and $35 \%$ for Tower 1 and Tower 2 .

Table 3. Electric Power Energy Saved At Average Used Between Day And Night

\begin{tabular}{rrrr}
\hline & Average kW Day & Average kW Night & Energy Saved \% \\
\hline Block 3 & 71.51 & 66.34 & $8 \%$ \\
Block 4 & 146.21 & 97.38 & $50 \%$ \\
Block 5 & 170.85 & 145.60 & $17 \%$ \\
Tower 1 & 96.77 & 58.69 & $65 \%$ \\
Tower 2 & 96.39 & 71.40 & $35 \%$ \\
\hline
\end{tabular}

\section{CONCLUSION}

This research has presented success analysed of electric power energy consumption at a campus university. Five buildings have been identified as scope in this research where power smart meter is installed for electric power usage data is collected. Research presents analysed data that shows result on power energy consumption on maximum and minimum energy consumption for day and night. Results presents that block 5 provides highest energy consumption at working hours and non-working hours compared to block 3 provides the lowest energy consumption at working hours but tower 1 presents lowest energy consumption at non-working hours. Overall analysed Tower 1 present the most energy saved at night which is 65\% compared to block 3 which is $8 \%$ saved energy although block 3 presents the lowest energy consumption in the working hours and non-working hours. A design prototype mobile application for smart meter to read the real-time is established but some technical errors occurred during the transmission data process form the database. Thus, some improvements are to be done for the developed real-time mobile application monitoring on the electric power energy consumption. The improvements is the time interval for data collection is to be in short interval from 15 minutes to 5 minutes where less memory needed for mobile apps adding the real time online data display. Future implementation is comparison between faculties of energy consumption can be analyzed based on an insight usage, efficiency and potential problems associated with power consumption.

\section{ACKNOWLEDGEMENT}

The author wish to thank Universiti Teknologi MARA (UiTM) and the Ministry of Higher Education (MoHE) for the support grant of 600-IRMI/DANA 5/3/LESTARI (0017/2016) in this research.

\section{REFERENCES}

[1] Rajamanickam S, Vijayalakshmi C. Design and Analysis of Lagrangian Algorithm for Power Flow System using Renewable Energy Resources. Indonesian Journal of Electrical Engineering and Computer Science. 2017;7(2):348-55.

[2] Syafiqah Z, Irwan Y, Amin N, Irwanto M, Leow W, Amelia A. Thermal and Electrical Study for PV Panel With Cooling. Indonesian Journal of Electrical Engineering and Computer Science. 2017;7(2):492-9.

[3] Razak IAWA, Abidin IZ, Siah YK, Abidin AAZ, Rahman TKA, Baharin N, et al. An Hour Ahead Electricity Price Forecasting with Least Square Support Vector Machine and Bacterial Foraging Optimization Algorithm. Indonesian Journal of Electrical Engineering and Computer Science. 2018;10(2).

[4] Rastogi S, Sharma M, Varshney P. Internet of Things based Smart Electricity Meters. International Journal of Computer Applications (0975-8887) Vol. 2016:13-6.

[5] Liu J, Yu J, editors. Research on development of android applications. Intelligent Networks and Intelligent Systems (ICINIS), 2011 4th International Conference on; 2011: IEEE.

[6] Yahaya CKHCK, Kassim M, bin Mazlan MH, Bakar ZA. A framework on halal product recognition system through smartphone authentication. Advances in Automation and Robotics, Vol 1: Springer; 2011. p. 49-56.

[7] Wei C-C, Yu C-H, Chiang L, Gong H-M, Huang Y-F. Implementation of an Integrated Mobile Solar Power Monitoring System for Images and Battery Parameters. Third International Conference on Computing Measurement Control and Sensor Network. 2016:1.

[8] Haroswati CK, Yahaya CK, Ismail MN, Kassim M, editors. A study on automated, speech and remote temperature monitoring for modeling WEB based temperature monitoring system. ICETC 2010 - 2010 2nd International Conference on Education Technology and Computer; 2010.

[9] Karimzadeh M, Valtulina L, van den Berg H, Pras A, Liebsch M, Taleb T, editors. Software Defined Networking to support IP address mobility in future LTE network. Wireless Days, 2017; 2017: IEEE. 
[10] Nayebi F, Desharnais J-M, Abran A. The State Of The Art Of Mobile Application Usability Evaluation. 2012 25th IEEE Canadian Conference on Electrical and Computer Engineering (CCECE) 2012.

[11] Palacios-Garcia EJ, Rodriguez-Diaz E, Anvari-Moghaddam A, Savaghebi M, Vasquez JC, Guerrero JM, et al. Using smart meters data for energy management operations and power quality monitoring in a microgrid. 2017;IEEE 26th International Symphony Industrial Electron pp. 1725-1731, 2017.

[12] Zhou S, Brown MA. Smart Meter Deployment in Europe: A Comparative Case Study on the Impacts of National Policy Schemes. Journal of Cleaner Production, volume 144, pp. 22-32, feb 2016.

[13] Dae-Man, Jae-Hyun L. Design and implementation of smart home energy management systems based on zigbee. Consumer Electronics, IEEE Transactions on, 2010. 56(3): p. 1417-1425.

[14] Rahman MM, MTO A. Technologies required for efficient operation of a smart meter network. (Industrial Electronics and Applications (ICIEA), 2011 6th IEEE Conference on. 2011.

[15] yuan Xu F, Zhou L, Wu YL, Ma Y, editors. Standards, policies and case studies in smart metering. Power and Energy Society General Meeting, 2010 IEEE; 2010: IEEE.

[16] Krishnanand KR, Prasad B, Chinh HD, Rathore AK, Panda SK. Smart-Metering for Monitoring Building Power Distribution Network using Instantaneous Phasor Computations of Electrical Signals. IECON Proc. Industrial Electron. Conf., pp. 2180-2184, 2013.

[17] Yu WS, Fang YJ. Data analysis of the smart meters and its applications in Tatung University. International Conference Fuzzy Theory 2016.

[18] Khatami R, Parvania M, Khargonekar P. Scheduling and Pricing of Energy Generation and Storage in Power Systems. 2017 IEEE Canadian Conference. Electric Computer Engineering volume 8950, no. c, pp. 1-14, 2017.

[19] Albano OA, Maciel CD, Cichy EC, Gongora VL, Pereira AA, Barbosa LR. Active and Reactive Power Energy Improving The Grid Quality Active and Reactive Power Energy Improving The Grid Quality. pp. 1-4, 2006.

[20] Guy-Ifergan N, Pikus D, Ben-Harrush I, Eisenberg V. Configuration Service for Mobile Apps. 2017 IEEE/ACM 4th International Conference on Mobile Software Engineering and Systems (MOBILESoft) 2017.

[21] Karimzadeh M, Valtulina L, Berg Hvd, Pras A, Liebsch M, Taleb T. Software Defined Networking to Support IP Address Mobility in Future LTE Network. 2012 25th IEEE Canadian Conference on Electrical and Computer Engineering (CCECE) 2012. 